\title{
The Market Environment of Survival for Large cost Chinese Costume Commercial Movies
}

\author{
Xiao han \\ Chongqing Electronic Engineering, Chongqing, Shapingba, 401331, China
}

Keywords: Big-cost Chinese Costume Movies, Lunar New Year Schedule, Box Office, Overseas Marketing, Hero, Red Cliff, Cultural Compatibility

\begin{abstract}
This year, in the Chinese Lunar New Year period battle of homemade films, a movie named "Lost In Thailand" turned out to win large number of people's attention successfully. On the contrary, "The Last Supper" and "The Guillotines", which are more familiar and large cost commercial movies for audience, crumble one after another and suffer losses on both reputation and box office. "Hero", directed by Zhang Yimou and released ten years ago, opened the era of Chinese big-cost commercial movies. At the same time, it created 250 million yuan tremendous box office which amounted to $1 / 4$ of the total box office in Chinese mainland movie market in that year.Ten years later, the year's gross of box office in the Mainland soared up to 17 billion yuan while large number of domestic films were still struggling for getting 100 million yuan box office. In past 10 years, Chinese costume commercial movies increased only in the quantity but not in the quality and market profit. The new ideas in these movies are less and less. The costume commercial movies are stepping on a unknown road which towards to a dead end? Filmmakers need to face these problems directly.This paper will try to analyze the market environment of survival for big-cost Chinese costume commercial movies by studying their development process.
\end{abstract}

\section{The glorious development history of Chinese costume blockbusters}

In the last ten years, which from the end of 20th century to the beginning of the 21st century, the most important and striking phenomenon about Chinese film industry was that "Chinese costume blockbuster movie" sprang up and coexisted with ups and downs.The costume movies, such as "Hero", "House of Flying Daggers”, "The Promise "," The Banquet "," Curse of the Golden Flower "," The Warlords "," Forever Enthralled"," Red Cliff", were being released one after another. This time became the turning point of Chinese film industry. These movies had already become a inevitable common topic and important contemporary culture phenomenon because of their box office and the vast discussion accompanied.The disputes, issues, commendations, denigration about them had far exceeded the movies themselves.Chinese costume blockbuster movies appeared with inevitability, not unexpected.Actually, there has been a prelude for blockbuster in the last century , such as "The Emperor's Shadow" (1996) directed by Zhou Xiaowen and "The Emperor And The Assassin"(1998) directed by Chen Kaige, while "Crouching Tiger, Hidden Dragon"is the beginning of blockbuster in the next new century."Crouching Tiger, Hidden Dragon" was produced mainly by Columbia Pictures, however, the director and the actors were Chinese, which ensured the film's Chinese characteristics. The overseas success of "Crouching Tiger, Hidden Dragon" inspired the confidence of Chinese filmmakers to make more commercial blockbusters. Since that, they opened 
up a mass process mode for blockbusters.Consequently, more blockbusters like "Hero," "House of Flying Daggers," "The Banquet" stepped into the skyrocketing period.

It is obvious that there were lots of problems about Chinese costume blockbusters, which often suffered from the serious split stricken in box office and uneven comment.Nevertheless, they seemed to have the ability of self-adjustment since some of them had get rid of the single costume element and martial arts model. They tried to change or transformed into the "post-blockbuster" era.Thus, the "blockbusters" kept expanding on the concept and enlarging compatibility. The defined standard is no longer confined to the costume themes, but inclined to investment, operation and so on. After ten years' developing, the "common features" of Chinese costume blockbusters can be summarized as following:

They all have diversified investment sources, in addition to from China mainland, Taiwan, Hongkong and Macao, but also from the United States, Japan, South Korea.

Other ways are to sale the film copyright of the United States, Japan, South Korea and to collect the market demand.All of these Investment were relatively large.

They all focus on the scene building, showing elements of Chinese culture. To some degree, they usually implant Chinese traditional culture and transform aesthetics spiritual for regeneration. Furthermore, they also focus on freehand aesthetics, visual spectacle expression, which eventually lead to the weakening of story and literariness.

They usually use super stars and famous directors to strength marketing and advertising. This is so-called marketing mode of large cost commercial movies, that is to spend numerous money on star line-up and marketing.

\section{The dead end signal of Chinese costume commercial movies in recent years}

Taking a little look back at the two years of the mainland film market, you will find that the box office failure of "The Last Supper" and "The Guillotines" is not a news for Chinese costume commercial movies.Last year, the National Day period, "Bronze Swallow Terrace", led by Chow Yun-Fat, collected nearly 100 million yuan in ticket receipts. Compared with 130 million yuan investment, it is still a money-losing proposition. The same as "Bronze Swallow Terrace", another 4 costume commercial movies such as "Warring States", "Ghost Story", "The lost bladesman", "Swordsmen", all released in 2011, also collected so less ticket receipts that can not even cover the investments. The truth is, over the past two years, only 2 costume commercial movies make real profits. They are "Painted Skin II"and "Flying Swords of Dragon Gate".

Knowing that it is difficult to make profits, why there are still more costume commercial movies constantly being produced?The reason is that, under the current Chinese movie authoring environment and a variety of restrictions, costume commercial movies are relatively easy to operate. Another reason is that there are many ready-made cases can be copied. It is in line with the characteristics of post modern cultural property in modern society.After so many years' practicing, it is so easy to make a costume commercial movie for most of Chinese film makers. This becomes a regular habit in making Chinese movies in recent 10 years. In stead, lacking of successful cases, it is much more difficult to shoot sci-fi disaster commercial movies. The blockbuster needs large cost advertising, which means more opportunities on the market, it might fall through, but the rate of success will be much higher than the average cost and small cost movies.

On the other hand, for the producers, perhaps only by a large cost costume commercial movie, they can establish their identity of great director or great film-make company in film industry. 
Behind the identity, it is the main purpose to gain commercial interests and authority. Straightly speaking, the large cost costume commercial movies is the symbol of vanity reputation to a greater extent.For some investors, their blindness for film industry also affect investment decisions.Under the joint effect of various factors, Chinese commercial movies disappeared from the film market one by one.Now, we need to clearly address the plight of large cost costume commercial movies.Through material researching, large cost Chinese costume commercial movies have several possibility of failure as following:

The Chinese large cost visual aesthetics commercial movies, which pioneered by "Hero" and "House of Flying Daggers", enjoyed their best time for those initial years due to the limited commercial movie quantity and deep desire of audience.Ten years later, Chinese costume commercial movies are still constantly publicize their huge visual appearance, lacking of further exploration for the narrative logic within the genre film. These commercial movies, which bulk copied on themes and visual performance, can not attract audience any longer.

A story about Banquet at Hongmen had contributed many so-called costume commercial movies in just two consecutive years. This shows the short of creativity in film industry. If film makers have any chance to find the treasure in the history of resources, they will just pick up the floating jewelry on the surface, but too lazy to dig deep to explore other topics which are more freshness and more valuable.We assume that it was because of freshness that visitors swarmed to see the "hero" and "House of Flying Daggers". But then, those costume commercial movies with repeated topics, similar style and old fashion stories consumed audience's initial enthusiasm.There will be nothing unique if costume commercial movies are still produced repeatedly.

The "Martial arts" is not just a world of imagination but also a cultural spiritual sustenance. The martial arts focus on chivalry. The spirit, that is to sacrifice oneself for the benefit of the common people,advocated by Mozi, show chivalrous spirit earlier. The violence expression in Chinese commercial movies seems to completely get rid of moral restriction and value of content. They turn to violent worship and aesthetics of violence, which run counter to martial arts chivalry. Most domestic commercial movies, like "The Banquet" and "Curse of the Golden Flower", usually choose to express revenge topics.However, all the avenger and people be revenged, rulers and rebels, people on behalf of the authority and order or insurgents, challenger, no one on behalf of justice and conscience. They don't have any justification when they use violence for revenge in addition to meet their own power and desire.Because this kind of hatred is valueless, the killing caused by hatred can only be indiscriminate violence.

Take "Red Cliff ( I)" for example, this costly film, based on the well-known Red Cliff Battle in the Three Kingdoms stories, tried to create a classic grand narrative. Unfortunately, the main characters in the film were obviously different with true history and the inherent minds of the three characters in audience, which caused people to reject the film in their mind.

\section{The development of Chinese costume commercial movies.}

In fact, the key point is not just the methods and strategies, but whether raise new questions or not, whether have enough new idea in theme and art or not. In short, the creativity is more essential no matter how commercial and amusing a movie is. People might have a misconception that commercial films and genre films are all programmable and routine, so they do not require much innovation especially new ideas and philosophy, just like the previous remarks quoted what Zhang Yimou said. This is a big mistake.In fact, new ideas and philosophy are just different in specific 
weight ratio and share configuration for commercial films, not the problem of unnecessary.In short, regardless of partition, ideological or philosophical always account for a certain share of the structure, especially new ideas or philosophy, including innovation on artistic expression of course, is the essential for all outstanding commercial and genre films.It is well-known that providing new ideas and art resources for humans is always a fluttering flag over all the art area. There is no exception for commercial blockbuster naturally. For example, "The Matrix" related to new digital world at least. "The Fifth Element" issued "lack of love" warning for humanity today. "Titanic" wanted to salvage the lost love and humanity. "X-Men" related to "specific function people "issues. "The Da Vinci Code " related to western complex religious culture, science and cultural background, however, these consideration in this movie such as Jesus is mortal and specificity, ordinary people would have been divine, keep the faith in humanity, were undoubtedly the forefront of the times. The main concern of Chinese blockbuster is precisely just the super landscape and new motion of the martial arts, without considering the new theme and philosophies. Now, take "The Promise" for an example.Undoubtedly, "The Promise" , which developed the magical route of "Warriors of Heaven and Earth" and "The myth", completely turned to the "Symbolized Fable Type" which led costume motion blockbuster into a completely different world. Its spirit of exploration and the pursuit of innovation is worthy of recognition. In "The Promise", it is easy to find the similarity with "Throne of Blood", "Run Lola Run," "Lord of the Rings" and so on, however, its spirit of exploring and innovation can not be ignored. Nevertheless, we also can not deny it is a failure of exploration in spite of its exploration and innovation. The problem is too subjective and too conceptual.Especially, the film makers do not understand the art rules of fantasy film and allegorical films. They also do not know how to change their film into genre film. In stead, unnecessary "Genre Assumption" make the entire film seem phony in genre and neither fish nor fowl. Since there was no real, believable, touching performance basis, it made actors blindness, incompetent. They can just performance some abstract symbol of ideas and looks like contrived. The audience also don't know what they are watching because it is difficult to get a glimpse about the "mystery" inside and it is difficult to enter the predetermined acceptable situation. According to the data revealed, the director's intention was to interpret several important concepts: fate, freedom and love. However, who can deny that this is just the director's own wish? As a result, "The Promise" is not a piece exploring films or art films, also not a commercial films because it can not make people relaxed and happy. The reason probably is that the aspiration of Chen Kaige about exploration films, philosophical films and artistic films is so rush that he can not "nirvana" to transform into commercial films at once. The effect would surely be better now if "The Promise" was really like "Throne of Blood," "The lord of the Rings" or "A Chinese Odyssey", "A Chinese Tall Story". In a word, the main reason why "The Promise" failed is the incorrect conceptualization and genre, that is to say, it looks like a "Transcendence", but its "innovative" was strangled by conceptualization, falsehood and contrived. Any kind of "new" in art should ultimately be seamless integrated into its artistry, rather than abstract "symbolic" and preaching. At the same time, "The Promise" did not take the comedy route which entertaining "joking" or "happy ending", but still basically confined to serious drama. They want earnest "grand narrative" but powerless. The result is that "The Promise" is not like serious drama but also without any entertainment. Finally, it is just a movie without both earnest and entertainment, also neither fish nor fowl. We don't mean that no one can choose the route of serious drama. The right way should be pay more attention on innovation of "entertaining", "consumption" structure codes arranged and the structure type. In 
short, Chinese costume action movies are still far from maturity if we compared them with standard commercial movies which based on history consumption, culture consumption, luxury landscape images consumption, drama story consumption, advanced ideas consumption. For example, "The Promise", "The Banquet", "Curse of the Golden Flower" will be "meaningless" if we measure them with the standard of humanity or innovative", because it didn't "surpass" anything and also didn't provided any new value and meaning. Furthermore, it had no entertaining element at all.

\section{Conclusion}

Chinese costume blockbusters are in the first important place. They still have long way to go. We must make great efforts to do it better. Costume theme movies have appeal in the international community because they are the representative of Eastern culture in the eyes of many Western countries' people. "Costume is a cultural cues. To choose costume is to choose a culture".

\section{References:}

[1] Chinese Blockbusters' Overseas Marketing and Strategy, Chen Xuguang, Modern Communication the 3rd issue 2011.

[2] The Banquet: The Fate of Chinese-style Blockbuster, Yin Hong, The Arts of movie the 1st issue 2007.

[3] "Contradiction" and the Reason - A Glimpse the Crux of Current Chinese Costume by analyzing Wheat Field, Yang Chen, Culture and Arts Studies the 4th issue 2009.

[4] The difficult growth of "Genre" films: industry, aesthetics and culture, Chen Xuguang, Art criticism, "Literature Contention" the 2nd issue 2011.

[5] The Aesthetic Cultural Reflection of Chinese Costume Blockbusters, Liu Yan, Film Comment, the 11th 2009.

[6] The Spread Elements Defect of Chinese Costume Action Blockbusters, Wang Ruijuan, Young Reporters the 12th issue 2008.

[7] The Problems and Way Out of Chinese Costume Action Movies, Yang Chu, Literary Studies, the 8th issue 2007. 